\title{
A Comparative Clinical Study of Oral Clonidine versus Intravenous Clonidine for Attenuation of Haemodynamic Response to Endotracheal Intubation
}

\author{
Dr. Mamatha .H. K ${ }^{1}$, Dr. Bindu George ${ }^{2}$ \\ Department of Anaesthesiology,St Johns Medical College,Bangalore,Karnataka,India-560034
}

\begin{abstract}
:
Background And Objectives: Laryngoscopy with or without tracheal intubation amounts to a highly noxious stimulus to the homeostasis of the patient. Many a times under lighter planes of anaesthesia it elicits a defence mechanism in the form of haemodynamic response to stress, which involves activation of adrenocortical system. This study was conducted to compare the effects of oral Clonidine and IV Clonidine premedication on haemodynamic response to laryngoscopy and endotracheal intubation.

Method: One hundred normotensive patients between 18-45yrs of age (ASA Grade I \& II) scheduled for elective surgery were sub-divided into two groups with 50 patients in each group. Group-I received oral Clonidine $4 \mu \mathrm{g} / \mathrm{kg}$ and Group-II received intravenous Clonidine $3 \mu \mathrm{g} / \mathrm{kg} 60$ minutes and 15 minutes before induction respectively. Induction was done with inj Propofol $2 \mathrm{mg} / \mathrm{kg}$ and inj Atracurium $0.5 \mathrm{mg} / \mathrm{kg}$ or inj Vecuronium $0.1 \mathrm{mg} / \mathrm{kg}$. Heart rate(HR), Systolic blood pressure(SBP), Diastolic blood pressure(DBP), Mean blood pressure (MBP) were recorded at preinduction, post-induction (pre-laryngoscopy) and post-laryngoscopy (1minutes, 3minutes, 5minutes, 10minutes \& 15minutes).
\end{abstract}

Results: Heart rate, Systolic blood pressure, Diastolic blood pressure, and Mean blood pressure increased by 3 minutes post-laryngoscopy in both groups. But the response was significantly less in the IV Clonidine group as compared to the Oral group. All the variables returned towards baseline values by 10-15minutes postlaryngoscopy in either groups.

Conclusion: IV Clonidine $3 \mu \mathrm{g} / \mathrm{kg}$ premedication effectively blunted stress response to endotracheal intubation in ASA physical status I and II patients without causing adverse reactions. Oral Clonidine $4 \mu / \mathrm{kg}$ was less effective in blunting haemodynamic stress response.

Key words: attenuation of haemodynamic response; diastolic blood pressure; endotracheal intubation; heart rate ; IV Clonidine; laryngoscopy; mean blood pressur;Oral Clonidine; Premedication; systolic blood pressure;

\section{Introduction}

Laryngoscopy and intubation are the most essential tools of an anesthesiologist in the airway management . Being a stressful stimuli, laryngoscopy and intubation are associated with significant sympathetic response, which though transitory and without sequel in healthy individuals, are detrimental in patients with pre-existing coronary artery disease, hypertension, cerebrovascular diseases etc ${ }^{[1][2]}$.

To overcome these undesirable responses many strategies that minimize the hemodynamic adverse responses have been tried ${ }^{[3]}$. But no single drug or technique has been satisfactory ${ }^{[3]}$. In the recent decade there has been a focus on a newer group of drug i.e. $\alpha_{2}$-adrenergic agonists like Clonidine and Dexmeditomedine.

Previously Clonidine was available only as oral preparation, but now with the advent of IV Clonidine, premedication time can be reduced from $60 \mathrm{~min}$ (as with oral clonidine) to $15 \mathrm{~min}$ pre-induction. Not many studies done previously have compared oral and intravenous clonidine in suppression of intubation response. Hence we chose to study the effectiveness of IV clonidine over oral clonidine in suppressing the hemodynamic responses to laryngoscopy and intubation.

\section{Methods}

100 ASA I and II patients of either sex, aged between 18-45yrs, undergoing elective orthopedic, spine, otorhinolaryngeal,gynecological and general surgical procedures under general anaesthesia participated in the study. ASAIII and IV, age $<18 \mathrm{yrs}$ and $>45 \mathrm{yrs}$, emergency procedures and patients with anticipated difficult intubation were excluded from the study.

A written and informed consent was obtained from each patient and the study was approved by our institution's ethical committee.

The study population was subdivided into 2 groups of 50 patients each. Group I (oral Clonidine group)received Tab Clonidine $4 \mu \mathrm{g} / \mathrm{kg}$ orally $60 \mathrm{~min}$ before induction with sips of water. Group II(IV Clonidine group)received inj Clonidine $3 \mu \mathrm{g} / \mathrm{kg}$ IV $15 \mathrm{~min}$ before induction. 
On arrival in the operation room, under standard monitoring(comprising of ECG,pulse oximetry, NIBP)patient was premedicated with inj Glycopyrrolate $0.2 \mathrm{mg}$ and ondonsetron $4 \mathrm{mgIV}$. After preoxygenation for 3min, general anaesthesia was induced with inj Propofol $(2 \mathrm{mg} / \mathrm{kg}) \mathrm{IV}$, muscle relaxation achieved with inj Atracurium(1mg/kg)IV OR inj Vecuronium $0.1 \mathrm{mg} / \mathrm{kg}$, followed 3min later by laryngoscopy and endotracheal intubation using 3 or 4 sized Macintosh blades and intubation with appropriate sized oral cuffed endotracheal tube done, by a resident with more than one year experience in anaesthesiology . Duration of laryngoscopy minimized to $30 \mathrm{sec}$. All cases with duration of laryngoscopy and intubation of more than 30sec were excluded from the final analysis.

Anaesthesia was maintained with 0.8-1MAC of Isoflurane in $\mathrm{O}_{2}(40 \%)$ and $\mathrm{N}_{2} \mathrm{O}(60 \%)$ mixture and atracurium as relaxant. Patients were ventilated mechanically with tidal volume of $8-10 \mathrm{ml} / \mathrm{kg}$ and respiratory rate of $12 / \mathrm{min}$. Analgesia with inj Fentanyl $1 \mu \mathrm{g} / \mathrm{kg}$ I.V supplemented if deemed necessary.

Concomitantly blood pressure(SBP,DBP,MBP) via NIBP and Heart rate through continuous ECG monitoring were recorded by a single observer, preinduction, post induction(pre-laryngoscopy) and, at one, three, five and fifteen minutes after laryngoscopy and intubation in both groups.

Statistical analysis was done by descriptive data presented as Mean \pm SD in percentage. Pair wise comparison between the groups was done by "T" test. For all tests $\mathrm{P}$ value of $<0.05$ was considered significant.

\section{Results}

No significant differences were observed between patients randomly assigned to the two groups with regard to age, sex and weight. $64 \%$ of the study population in the oral clonidine group and $62 \%$ in the IV clonidine group were males. No patients were excluded from the study.

1.1. Heart rate: The basal(pre-induction) heart rate was not comparable. Heart rate rose post laryngoscopy and intubation. The difference between oral and IV group was statistically significant only after $5 \mathrm{~min}$ post laryngoscopy, being very significant at $10 \mathrm{~min}$ and $15 \mathrm{~min}$ post laryngoscopy $(\mathrm{p}<0.05)$. The mean heart rate for oral clonidine group ranged between $80.08 \pm 8.63$ to $100.7 \pm 8.79$. On the other hand the mean heart rate for the IV group ranged between $82.2 \pm 8.69$ to $97.14 \pm 10.8$. The maximum rise from baseline being $26 \%$ in the oral group (at $3 \mathrm{~min}$ ) and $18 \%$ in the IV group.

Table 1: Showing heart rate variations (Beats/min)

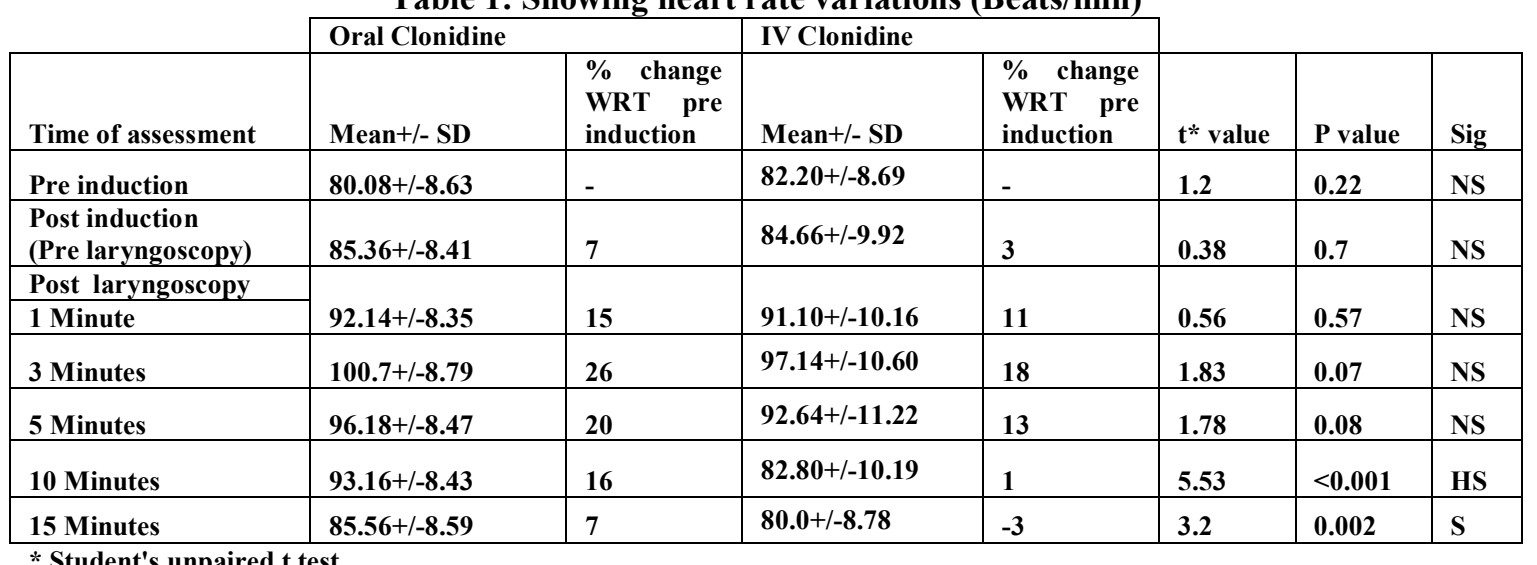

* Student's unpaired $t$ test

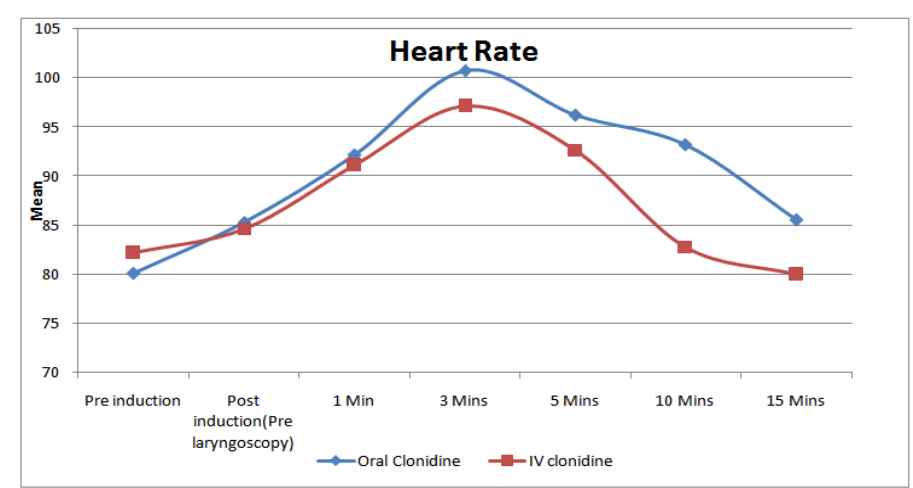

Fig 1: Line diagram showing variations in heart rate in the IV and oral Clonidine groups 
1.2. Systolic blood pressure: The basal (pre-induction) systolic blood pressure and standard deviation in the IV clonidine group was $118.18 \pm 18.06$ compared to the oral group which was $126.76 \pm 7.89(\mathrm{P}<0.05)$. In our study there was a highly significant difference $(\mathrm{P}<0.001)$ in systolic blood pressure with oral and IV clonidine groups at $1 \mathrm{~min}$ post laryngoscopy. A maximum rise in systolic blood pressure in the oral group was seen at $1 \mathrm{~min}$, which was $12 \%$ above baseline, while it was $10 \%$ in the IV group seen at $3 \mathrm{~min}$. The systolic blood pressure remained high till 10min post laryngoscopy in oral group, while it reached the baseline value by $5 \mathrm{~min}$ in the IV group.

Table 2: Showing variations in Systolic Blood Pressure (mm Hg)

\begin{tabular}{|c|c|c|c|c|c|c|c|}
\hline & \multicolumn{2}{|l|}{ Oral Clonidine } & \multicolumn{2}{|l|}{ IV Clonidine } & \\
\hline $\begin{array}{ll}\text { Time } & \text { of } \\
\text { assessment }\end{array}$ & Mean+/- SD & $\begin{array}{l}\text { \% change } \\
\text { WRT pre } \\
\text { induction }\end{array}$ & Mean+/- SD & $\begin{array}{l}\text { \% change } \\
\text { WRT pre } \\
\text { induction }\end{array}$ & $\begin{array}{l}t^{*} \\
\text { value }\end{array}$ & $\begin{array}{l}P \\
\text { value }\end{array}$ & Sig \\
\hline Pre induction & $126.76+/-7.89$ & - & $118.18+/-18.06$ & - & 3.07 & 0.003 & $\mathbf{S}$ \\
\hline $\begin{array}{l}\text { Post } \\
\text { induction(Pre } \\
\text { laryngoscopy) }\end{array}$ & $114.42+/-8.69$ & -10 & $102.3+/-10.64$ & -13 & 6.23 & $<0.001$ & HS \\
\hline Postlaryngoscopy & & & & & & & \\
\hline $1 \mathrm{Min}$ & $142.8+/-8.13$ & 12 & $125.56+/-9.95$ & 6 & 9.04 & $<0.001$ & HS \\
\hline 3 Mins & $139.14+/-7.22$ & 10 & $130.26+/-9.21$ & 10 & 5.36 & $<0.001$ & HS \\
\hline 5 Mins & $132.92+/-6.40$ & 5 & $125.92+/-9.14$ & 7 & 4.43 & $<0.001$ & HS \\
\hline 10 Mins & $129.64+/-6.79$ & 2 & $121.69+/-9.7$ & 3 & 4.73 & $<0.001$ & HS \\
\hline 15 Mins & $128.02+/-6.86$ & 1 & $118.86+/-9.65$ & 1 & 5.46 & $<0.001$ & HS \\
\hline
\end{tabular}

* Student's unpaired t test

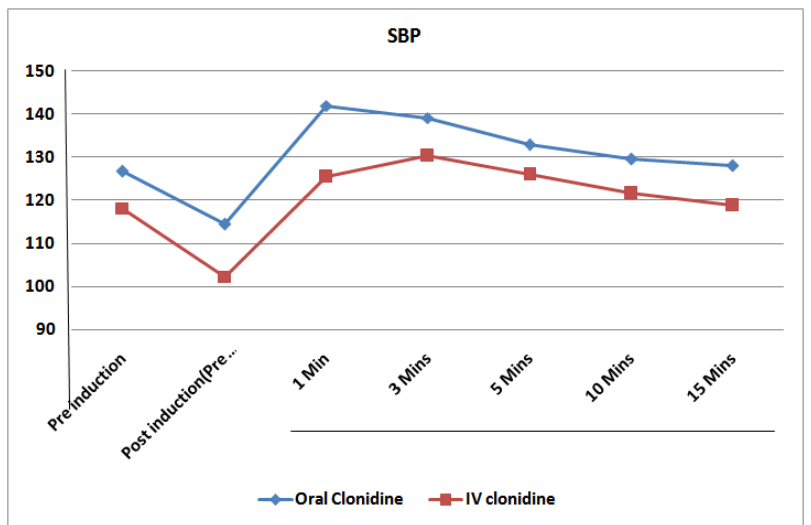

Fig 2: Line diagram showing variations in systolic blood pressure in oral and IV Clonidine groups

1.3. Diastolic blood pressure: The basal(pre-induction) mean and standard deviation of diastolic blood pressure was $76.3 \pm 6.29$ with the oral group and $73.84 \pm 5.60$ in the IV group which was comparable $(\mathrm{P}<0.04)$. In our study attenuation of diastolic blood pressure by IV group as compared to oral clonidine group was highly statistically significant until $10 \mathrm{~min}(\mathrm{P}<0.001)$ post laryngoscopy. A maximum rise of diastolic blood pressure was $13 \%$ above baseline for oral group while $10 \%$ above baseline for IV group both seen at $3 \mathrm{~min}$ post laryngoscopy.

Table 3: Showing variations in Diastolic Blood Presure $(\mathrm{mm} \mathrm{Hg})$

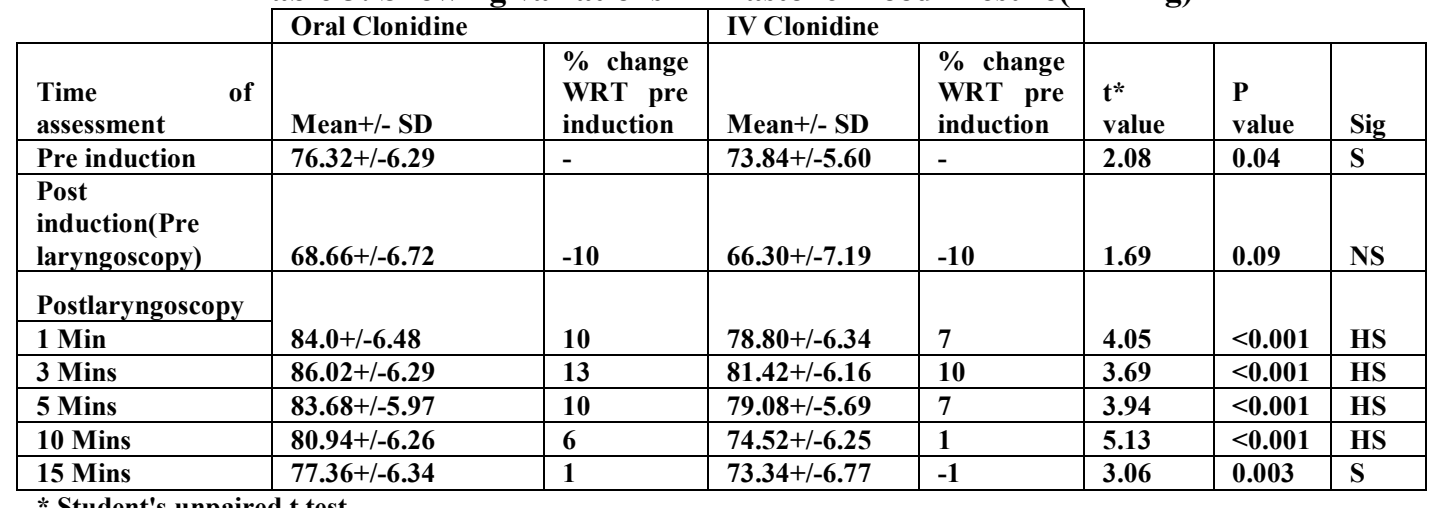

* Student's unpaired t test 


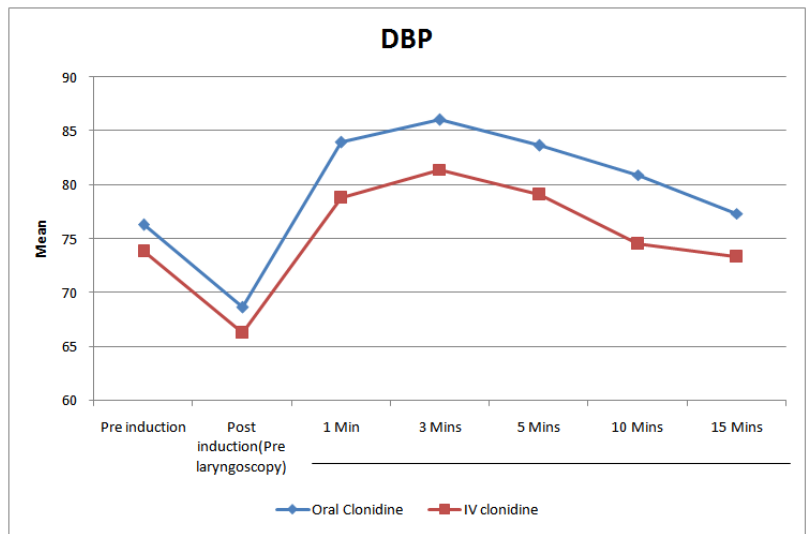

Fig:3: Line diagram showing variations in diastolic blood blood pressure in the IV and oral Clonidine groups.

1.4. Mean blood pressure: The mean and standard deviation of baseline mean blood pressure was $93.13 \pm 6.23$ and $89.05 \pm 6.04$ for oral and IV groups respectively which was comparable with a significant $\mathrm{P}$ value $(\mathrm{P}<0.001)$. The mean blood pressure showed a $11 \%$ rise $(103 \pm 6.6)$ from baseline at 1 and $3 \mathrm{~min}$ in the oral group , while mean blood pressure rose to $6 \%$ and $10 \%$ from baseline at $1 \mathrm{~min}$ and $3 \mathrm{~min}$ respectively with the IVgroup . A highly significant $\mathrm{P}$ value $(\mathrm{P}<0.001)$ was derived in comparing the two.Attenuation of mean blood pressure by IV clonidine group as compared to oral clonidine was highly significant at all intervals in post laryngoscopy period.

Table 4:Showing variations in Mean Blood Pressure(mmHg)

\begin{tabular}{|c|c|c|c|c|c|c|c|}
\hline & \multicolumn{2}{|l|}{ Oral Clonidine } & \multicolumn{2}{|l|}{ IV Clonidine } & \multicolumn{3}{|c|}{8} \\
\hline $\begin{array}{ll}\begin{array}{l}\text { Time } \\
\text { assessment }\end{array} & \text { of }\end{array}$ & Mean+/- SD & $\begin{array}{l}\text { \% } \\
\text { change } \\
\text { WRT } \\
\text { pre } \\
\text { induction }\end{array}$ & Mean+/- SD & $\begin{array}{l}\% \\
\text { change } \\
\text { WRT } \\
\text { pre } \\
\text { induction }\end{array}$ & $\begin{array}{l}\text { t* } \\
\text { value }\end{array}$ & $\begin{array}{l}P \\
\text { value }\end{array}$ & Sig \\
\hline Pre induction & $93.13+/-6.23$ & - & $89.05+/-6.04$ & - & 3.32 & 0.001 & $\mathbf{S}$ \\
\hline $\begin{array}{l}\text { Post } \\
\text { induction(Pre } \\
\text { laryngoscopy) }\end{array}$ & $83.93+/-6.88$ & -10 & $77.92+/-7.64$ & -13 & 4.13 & $<0.001$ & HS \\
\hline Postlaryngoscopy & & & & & & & \\
\hline $1 \mathrm{Min}$ & $103.14+/-6.66$ & 11 & $94.38+/-6.62$ & 6 & 6.59 & $<0.001$ & HS \\
\hline 3 Mins & $103.66+/-6.03$ & 11 & $97.70+/-6.08$ & 10 & 4.93 & $<0.001$ & HS \\
\hline 5 Mins & $99.96+/-5.37$ & 7 & $94.69+/-5.72$ & 6 & 4.75 & $<0.001$ & HS \\
\hline 10 Mins & $97.32+/-5.69$ & 5 & $90.35+/-6.17$ & 1 & 5.87 & $<0.001$ & HS \\
\hline 15 Mins & $94.24+/-5.92$ & 1 & $88.51+/-6.64$ & -1 & 4.55 & $<0.001$ & HS \\
\hline
\end{tabular}

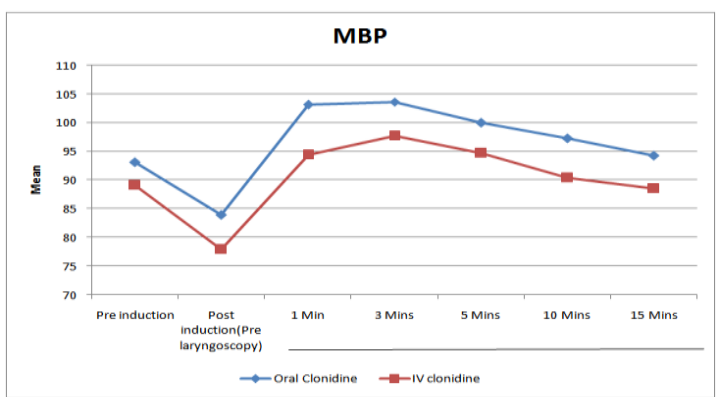

Fig 4: Line diagram showing variations in the Mean Blood Pressure in oral and IV Clonidine groups

\section{Discussion}

Induction of general anaesthesia, direct laryngoscopy and endotracheal intubation induce marked cardiovascular changes as well as autonomic reflex activity ${ }^{[4]}$. The response may be particularly hazardous for patients with cardiovascular and cerebrovascular diseases ${ }^{[5]}$. Attenuation of these hemodynamic responses is of great importance in prevention of per operative morbidity and mortality. Strategies to circumvent these changes have included minimizing the duration of laryngoscopy, IV narcotics, IV and topical lignocaine,vasodialators, 
$\beta$-blockers, calcium channel blockers, inhaled anaesthetics and epidural analgesia ${ }^{[6]}$. Although these drugs did obtund the cardiovascular response, they failed to fulfill the desired criteria of complete attenuation ${ }^{[7]}$.

Recently there has been considerable research in the $\alpha_{2}$ adrenergic agonist group of drugs in this respect. These drugs act at receptor site in medulla oblongata and presynaptically at peripheral nerve terminals, to cause a reduction in activity of sympathetic nervous system ${ }^{[8]}$. Clonidine, an imidazole compound is a selective agonist for $\alpha_{2}$ adrenoceptors with a ratio of $200: 1\left(\alpha_{2}: \alpha_{1}\right)$. Though primarily an antihypertensive,clonidine has been increasingly used for premedication ${ }^{[9][10]}$.

Its central action reduces sympathetic activity, producing sedation, anxiolysis, dryness of secretions with reduction in requirement of anesthetic agents and improved cardiovascular stability in the perioperative period $^{[11]}$. Clonidine premedication attenuates potentially harmful cardiovascular responses and hypertension during laryngoscopy and intubation ${ }^{[6]}$.

Within the last decade, several studies have reported the successful use of oral clonidine premedication to prevent hyperadrenergic and hyperdynamic cardiovascular responses to endotracheal intubation ${ }^{[12][13]}$.

However, there are not many studies comparing intravenous and oral applications of clonidine prior to induction of anaesthesia. In our study, the intravenous clonidine administration immediately prior to induction of anaesthesia was compared with the more conventional oral clonidine administration for alterations of heart rate, systolic blood pressure, diastolic blood pressure and mean blood pressure due to laryngoscopy and endotracheal intubation. Both groups were premedicated and anaesthetized similarly. Laryngoscopy and intubation in both the groups was done by residents with more than one year experience. The anaesthetic technique was chosen such that drugs administered did not show any significant hemodynamic changes.

Results of our study indicate that IV clonidine very effectively blunts the stress response due to endotracheal intubation in ASA physical status I and II patients compared to oral clonidine. This was evidenced by a significantly lesser incidence of heart rate and mean arterial pressure with IV clonidine.

Dose of oral clonidine $(4 \mu \mathrm{g} / \mathrm{kg}, 60 \mathrm{~min}$ prior to induction) was almost similar to previous studies $^{[12][13][14][15]}$. We chose to use this dose because; larger doses $(0.2 \mathrm{mg})$ of oral clonidine are known to induce hypotension and bradycardia, which are maximal at $60-90 \mathrm{~min}$ after oral administration ${ }^{[15]}$. Also the effects of oral clonidine on hemodynamic variables and sedation are dose related an increasing the dose to more than $4 \mu \mathrm{g} / \mathrm{kg}$ does not further enhance efficacy ${ }^{[16]}$. With IV clonidine changes of HR and MBP were dose related up to a dose $4 \mu \mathrm{g} / \mathrm{kg}$, increasing the dose to $6 \mu \mathrm{g} / \mathrm{kg}$ did not further enhance the hemodynamic effects and a dose of $2 \mu \mathrm{g} / \mathrm{kg}$ was found to be equal to placebo ${ }^{[16]}$. Hence we preferred to use a dose of $3 \mu \mathrm{g} / \mathrm{kg}$ for IV group. Considering the high bioavailability of oral clonidine $(95 \%)^{[17]}$ the IV dose $(3 \mu \mathrm{g} / \mathrm{kg})$ was relatively small compared with the oral dose. Yet IV clonidine appeared to provide better protection from hemodynamic response due to endotracheal intubation than did oral clonidine. However conclusions concerning dose efficacy relationship cannot be drawn from our data, because clonidine plasma concentrations were not compared. clonidine.

The following study parameters proved a clinical and statistical significance of intravenous over oral

1.5. HEART RATE: A statistically significant decrease in heart rate was observed with IV clonidine at $10 \mathrm{~min}$ and $15 \mathrm{~min}$ postlaryngoscopy. Maximum rise in heart rate were $26 \%$ and $18 \%$ with oral and IV groups at 3 min respectively.

1.6. ARTERIAL BLOOD PRESSURE: A statistically significant $(\mathrm{P}<0.001)$ attenuation of systolic blood pressure by IV clonidine as compared to oral clonidine group was observed through the post laryngoscopy period.Attenuation of diastolic blood pressure by IV clonidine as compared to oral clonidine was highly significant statistically $(\mathrm{P}<0.001)$ until $10 \mathrm{~min}$ post laryngoscopy.Our study showed a significant difference in the mean blood pressure with oral and IV clonidine throughout the post laryngoscopy period.

In addition to efficacy, both safety and applicability of IV pre induction clonidine administration are important for clinical practice. In contrast to the orally premedicated patients in the ward, the patients receiving IV clonidine are monitored and under the control of anesthesiologist in the operation room. This may be advantageous in patients with increased cardiac risk because undetected cardiovascular side effects of clonidine such as bradycardia and hypotension could be hazardous.

No serious side effects were observed even at doses of $6 \mu \mathrm{g} / \mathrm{kg}$ IV in studies investigating effects on stress response with intubation in CABG patients ${ }^{[16]}$. Clonidine has also been shown to improve congestive heart failure and has been successfully used to optimize myocardial oxygen-supply demand ratio in ischemic heart disease ${ }^{[10][11]}$.

Furthermore, the IV route of oral clonidine administration delays the induction of anaesthesia, but the administration of oral clonidine in the ward necessitates proper guiding of the nursing staff in the ward regarding the exact dosage and monitoring after administration of the drug.

The patients in the IV clonidine group were not premedicated and hence experienced the transport to the operating room as well as preparation for anaesthesia. Orally premedicated patients had to be accompanied 
by a trained nurse with continuous monitoring and the whole process needs to be planned on the previous day of surgery.

In comparison to the more usual oral clonidine premedication, IV preinduction clonidine administration $3 \mu \mathrm{g} / \mathrm{kg}$ appeared to be more effective, and regarding the lack of adverse reactions, atleast as safe and easy to apply in ASA physical status I and II patients. IV clonidine optimized hemodynamic stability during the induction of anaesthesia and decreased the doses of analgesics, IV induction agents and inhalational agents used at induction, intra operatively and post operatively.

\section{Conclusion}

To conclude, IV premedication with Clonidine, when compared to the traditional oral Clonidine, effectively attenuates the haemodynamic response to laryngoscopy and intubation of trachea. The ease of administration and the haemodynamic stability it offers, projects IV Clonidine as a useful and safe premedicant. Oral Clonidine though simple and cost-effective, it is less effective in blunting haemodynamic response to endotracheal intubation.

\section{References}

[1]. Fleisher LA. Peroperative myocardial ischemia and infarction. Int Anaesthesiol Clin. 1994;4:1-15.

[2]. Gill NP, Wright B, Reilly CS. Relationship between hypoxemia and cardiac ischemic events in the peroperative period. Br $\mathbf{J}$ Anaesth. 1992;68:471-473.

[3]. Vincent J Collins. Principles of Anaesthesiology. General and Regional anaesthesia, $3^{\text {rd }}$ edition ,Vol I and II Philadelphia: Lea and Fabigee

[4]. Russell W.J, Morris R.G, et al. changes in plasma catecholamine concentrations during endotracheal intubation. British Journal of Anaesthesia, 1981; 53:837-839.

[5]. T.E Black, B.Kay and T.E.J.Healy. Reducing the haemodynamic responses to laryngoscopy and intubation. A comparison of Alfentanyl and Fentanyl. Anaesthesia.1984; vol 39: pages 883-887.

[6]. Wycoff Charles. Endotracheal intubation;effects on blood pressure and pulse rate. Anaesthesiology.1960(Mar-Apr);21(2):153-157.

[7]. Dipak L.Raval, Malini K. Mehta. Oral clonidine premedication for attenuation of haemodynamic response to laryngoscopy and intubation. Ind J Anaesth. 2002; 46(2): 124-129.

[8]. Wright P.M, Carabine U.A, McClune S, Orr D.A, Moore.J. Pre-anaesthetic medication with Clonidine. Br. J. Anaesth. 1990; 65:628-632.

[9]. Laurito CX. Baughman, Becker, Cunningham F, Pygon BH. Oral Clonidine blunts the haemodynamic responses to brief but not prolonged laryngoscopy. J Clin Anaesth. 1993;5:54-7.

[10]. Giles TD, Thomas MC, Quirol A, Rice JC, Plauche W, Sander GE: Acute and short-term effects of Clonidine in heart failure. Angiology. 1987;38:53-48.

[11]. . Hermiller JB, Magorien RD, Leithe ME, Unverferth DV, Leier CV. "Clonidine in congestive heart failure: a vasodilator with negative inotropic effects". Am J Cardiol. 1983 Mar 1;51(5):791-5.

[12]. Chadha R, Padmanabhan V, Joseph A, Mohandas K. Oral Clonidine pretreatment for haemodynamic stability during craniotomy. Department of Anaesthesiology SCT, Trivandrum, India. Anaesthesia Intensive Care. 1992 Aug; 20(3): 341 -344.

[13]. Bloor BC,Flake WE. Reduction in halothane anaesthetic requirements by Clonidine ,an alpha adrenergic agonist. Anaesth and Analg. 1982;61:11-19.

[14]. Ghignone M, Quintin L, Duke PC. Kehler CH, effects of Clonidine on Narcotic requirements and Haemodynamic Response during induction of Fentanyl Anesthesia and Endotracheal intubation. Anesthesiology. 1986; 64: 36- 42

[15]. U.A. Carabine, P. M. C.Wright and J. Moore, Preanaesthetic medication with Clonidine:A dose-response study.Br J Anaesth. 1991;67:79-83.

[16]. Peter J. Kulka, MD ,Micheal Tryba,MD, and Micheal Zenz, MD.Dose response effects of intravenous clonidine on stress response during induction of anaesthesia in CABG patients. Anaesthesia \& Analgesia. February 1995;80(2): 263-268. 